\title{
HYDROGEN PASSIVATION IN SEMICONDUCTORS
}

\author{
M. Stavola \\ Physics Department and the Sherman Fairchild Laboratory, Lehigh University \\ Bethlehem, PA 18015, USA
}

A survey is presented of the structure, stability, and reorientation kinetics of acceptor- $\mathrm{H}$ and donor-H complexes in $\mathrm{Si}$ and III-V semiconductors. A few examples of the unintentional introduction of $\mathrm{H}$ into device materials are also discussed.

PACS numbers: $61.70 .-\mathrm{r}, 61.70 . \mathrm{Tm}$

\section{Introduction}

Hydrogen is ubiquitous in the environment and has gained recognition as an important impurity in semiconductors [1-4]. Ifydrogen can be introduced into semiconductors intentionally, for example from a hydrogen-containing plasma, or unintentionally during crystal growth or many of the subsequent stages of device processing. Once incorporated, atomic hydrogen diffuses rapidly and, in many cases, forms neutral complexes with crystal defects and impurities.

Even though a variety of hydrogen-related complexes were known that involve impurities in $\mathrm{Ge}[2,5]$ or deep levels defects $[2,6]$, it was the discovery of the passivation of shallow acceptors in $\mathrm{Si}[7,8]$ that launched a great many experimental and theoretical studies. Following the observation of acceptor passivation in $\mathrm{Si}$, the hydrogen-passivation of a variety of $n$ - and $p$-type dopants in elemental and compound semiconductors was demonstrated [1-4].

The fundamental understanding of hydrogen-related defects in semiconductors has improved greatly in recent years due to the strong interaction between experiment and computational theory $[4,9]$. The hydrogen-passivated shallow donor and acceptor impurities, which will be described in this paper, have become the best understood hydrogen-containing complexes.

\section{Dopant passivation}

Sah et al. [7] and Pankove et al. [8] discovered that shallow acceptors in $\mathrm{Si}$ could be passivated by atomic hydrogen. In the experiments by Sah et al. [7], the source of hydrogen was an oxide layer on the Si surface whereas in the experiments by Pankove et al. [8], $\mathrm{H}$ was introduced by exposing the samples to a hydrogen containing plasma. Both groups found that a high resistivity surface layer was created 
by the indiffusion of H. Spreading resistance profiles of boron doped Si are shown in Fig. 1a before and after exposure to a deuterium plasma [10]. Concentration profiles of boron and deuterium measured by secondary ion mass spectrometry (SIMS) are shown in Fig. 1b. It can be seen that the depth of the high resistivity surface layer corresponds well to the depth of deuterium incorporation measured directly by SIMS.
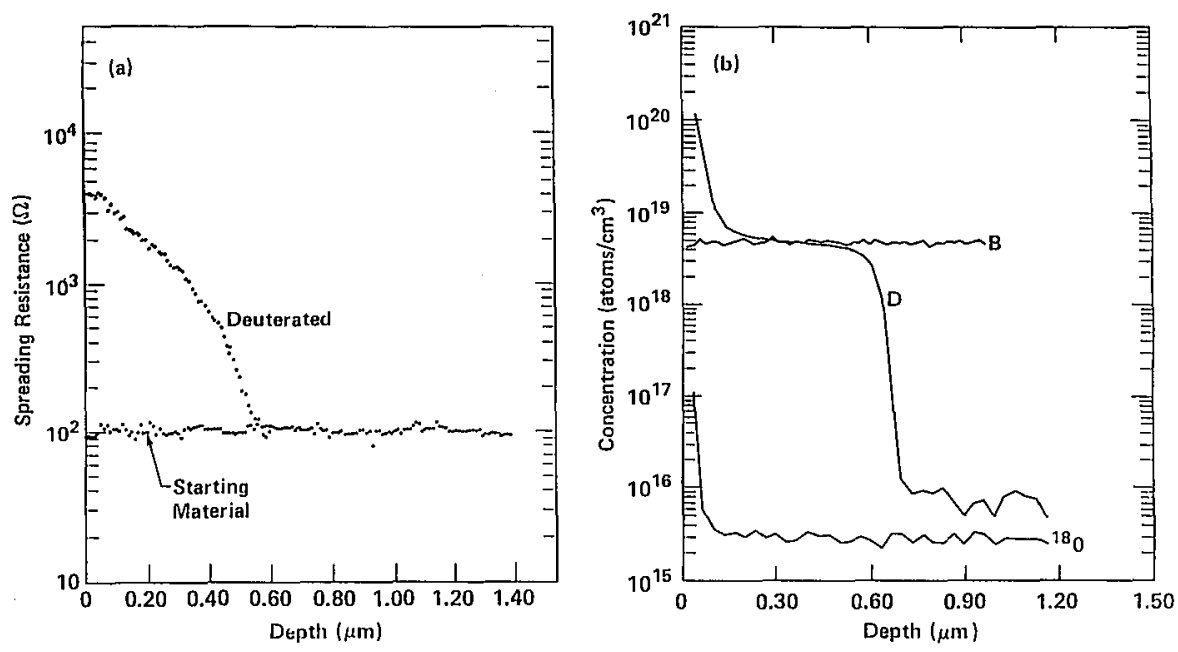

Fig. 1. Depth profiles of (a) the spreading resistance and (b) the deuterium and boron concentrations in boron-doped $\mathrm{Si}$ which had been exposed to a deuterium plasma for 30 $\min$ at $150^{\circ} \mathrm{C}$. From Johnson, Ref. [10].

Isolated, atomic hydrogen diffuses quickly in semiconductors [11-13] and is highly reactive. Hence, isolated $I I$ has proven to be difficult to study experimentally. Nonetheless, much progress has been made in recent years in determining the properties of isolated II [4]. Here, only a few remarks about isolated II, relevant to dopant passivation in $\mathrm{Si}$, are made.

Several theoretical calculations [4] find that in $p$-type Si, the lowest energy site for isolated $\mathrm{H}$ is at a bond-center between two silicon atoms. (A plot of formation energy for the different charge states vs. Fermi level position is shown in Fig. 2 [14].) In this configuration, the hydrogen has a donor state in the upper half of the band gap. The H-passivation of an acceptor impurity has been envisioned as first involving the compensation of the shallow acceptor by an $H$ donor [15]. The charged $\mathrm{H}^{+}$is then attracted to the negative acceptor; this long-range Coulomb attraction drives pairing of the acceptors with mobile $\mathrm{I}^{+}$. The final product is not a simple Coulomb pair but is a dopant-H complex in which covalent bonding plays a dominant role.

In $n$-type $\mathrm{Si}$, theoretical calculations find the lowest energy configuration for II near a tetrahedral interstitial site (Fig. 2) [4]. In this case, II has an acceptor level. The $\mathrm{H}$ acceptors might then compensate shallow donors in $n$-type $\mathrm{Si}$, hence, hydrogen will be in the $\mathrm{H}^{-}$charge state in $n$-type $\mathrm{Si}$. Pairing would again be driven 


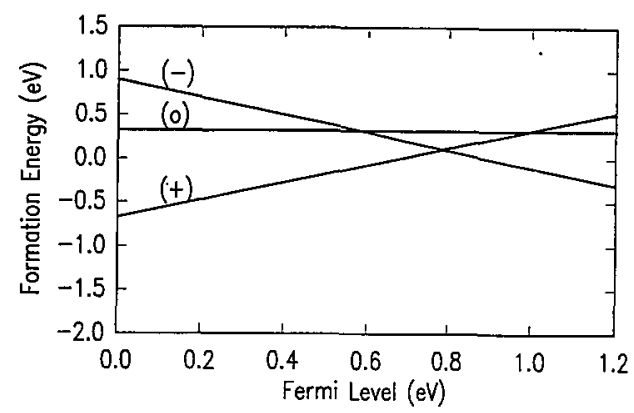

Fig. 2. Relative formation energies for different charge states of an interstitial II impurity in $\mathrm{Si}$. The zero of energy has been chosen as the energy of $\mathrm{H}^{0}$ at the $\mathrm{T}$ site. From Van de Walle et al., Ref. [14].

by Coulomb attraction, followed by the formation of a covalently bonded pair.

The field-induced drift of $\mathrm{H}^{+}$in $p$-type $\mathrm{Si}$ was observed by Tavendale et al. [16] and Johnson [17] in the space charge region of a diode. These observations provide strong evidence for the existence of $\mathrm{II}^{+}$in $p$-type $\mathrm{Si}$ and of the overall picture of acceptor passivation described above. More recently; field induced drift has been observed for hydrogen in $n$-type $\mathrm{Si}$ and interpreted as providing evidence for the existence of $\mathrm{H}^{-}[18,19]$. The latter interpretation has been controversial [20]. As will be discussed further in Sec. 4, the clever use of junction fields has yielded much valuable information on the properties of hydrogen.

While the above discussion has been about passivation in $\mathrm{Si}$, the situation is believed to be similar for acceptor and donor passivation in GaAs. Theory finds $[21,22]$ that $\mathrm{H}$ has donor and acceptor states in $p$-type and $n$-type GaAs, respectively. Field drift experiments have been performed [23-25] and the position for the II donor level has been estimated experimentally [26].

\section{Structure of dopant $-H$ complexes}

The structures of dopant-H complexes have been investigated by a variety of experimental methods, with vibrational spectroscopy being the most commonly used $[2,27]$. It has also been possible to determine the minimum energy configurations of dopant-hydrogen complexes and their vibrational frequencies with sophisticated, total-energy calculations [11]. Through the comparison of theory with measured vibrational frequencies and related data, the structures of several dopant-hydrogen complexes have been determined. In Si and III-V semiconductors, there are three structures for dopant-II complexes that have been found. These are shown in Fig. 3.

\subsection{Acceptor-H complexes}

The $\mathrm{B}-\mathrm{H}$ complex in $\mathrm{Si}$ is the most studied of the dopant-II complexes. The BC structure (Fig. 3a) was first suggested by Pankove et al. [28] on the basis of 
(a)

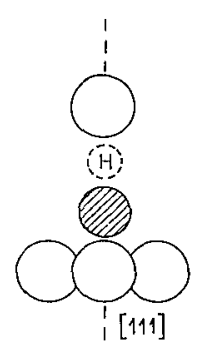

(b)

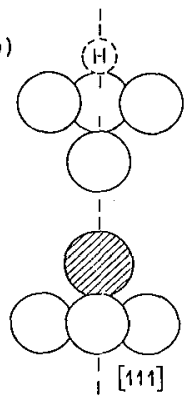

(c)

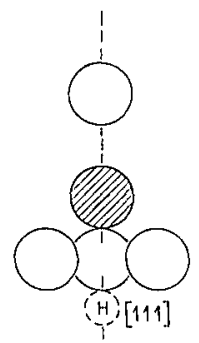

Fig. 3. Structures of dopant-H complexes. (a) The bond-centered (BC) configuration. (b) The antibonding $(\mathrm{AB})$ configuration with the $\mathrm{H}$ attached to the dopant's nearest neighbor. (c) The AB configuration with the $\mathrm{H}$ attached to the dopant atom.

the vibrational absorption band which they had observed at $1875 \mathrm{~cm}^{-1}$ for the complex. These authors argued that the $1875 \mathrm{~cm}^{-1}$ frequency was more typical of a $\mathrm{Si}-\mathrm{II}$ bond than a $\mathrm{B}-\mathrm{H}$ bond which has a higher frequency in typical molecules. IIence they proposed that the $\mathrm{H}$ was attached primarily to a $\mathrm{Si}$ atom and that the II atom should interrupt a $\mathrm{Si}-\mathrm{B}$ bond to leave the $\mathrm{B}$ atom tricoordinated.

DeLeo and Fowler [29] found that the total energy of the B-II complex was minimized for $\mathrm{II}$ at the $\mathrm{BC}$ site by cluster methods. While the $\mathrm{BC}$ configuration for the acceptor-II complexes was initially controversial [30], strong support has come from vibrational spectroscopy $[27,31,32]$, channeling experiments [33, 34], and scveral theoretical calculations [35-38].

There have been several reviews of the hydrogen-passivation of dopants in III-V materials written [39-41]. The passivation of acceptors in GaAs was first demonstrated for $\mathrm{Zn}_{\mathrm{Ga}}$ with capacitance-voltage $(C-V)$ measurements and SIMS profiles by Johnson et al. [42]. Subsequently, Pajot et al. discovered the II-stretching vibration at $2146.9 \mathrm{~cm}^{-1}$ due to GaAs: $\mathrm{Zn}-\mathrm{HI}$ [43]. Already in this early work, Pajot et al. suggested that the $\mathrm{H}$ is at the $\mathrm{BC}$ site between the $\mathrm{Zn}$ and an As neighbor with a configuration similar to Si:B-II. The frequency of the II-stretching band is close to that of As-II stretching modes in molecules which led Pajot et al. [43] to suggest that the $\mathrm{H}$ is attached primarily to the As atom.

Several studies of GaAs:Be-H help to confirm this picture of hydrogen complexed with Ga-site acceptors. The H-stretching band was found at $2037.1 \mathrm{~cm}^{-1}$ by Nandhra et al. [44] and the local mode due to isolated Be was also examined. This work proved the close association of $H$ and the acceptor atom in the passivated complex and led the authors to suggest a BC configuration for GaAs:Be-II. Strong support for the BC configuration is obtained from uniaxial stress experiments which show that the Be-H complex has trigonal symmetry [45] and from calculations $[22,46]$ which obtain an II-stretching frequency in good agreement with experiment $[44]$.

Vibrational bands have also been assigned for II complexed with the As-site acceptors in GaAs; the complexes that have been studied are $\mathrm{C}_{\mathrm{As}}-\mathrm{II}$ [26], 
$\mathrm{Si}_{\mathrm{As}}-\mathrm{II}$ [47], and $\mathrm{Ge}_{\mathrm{As}}-\mathrm{H}[40,41]$. The H-stretching spectrum for $\mathrm{C}_{\mathrm{As}}-\mathrm{H}$ due to Clerjaud et al. [26] is shown in Fig. 4. It was suggested that the complexes of II with the As-site acceptors also have a $\mathrm{BC}$ configuration but with the II attached primarily to the acceptor [39]. This model is strongly supported by the observed trend in the vibrational frequencies for the different acceptors, stress data $[48,49]$, and theory $[22,50]$.

The properties of passivated acceptors in InP [39-41] are similar to what has been observed for GaAs.

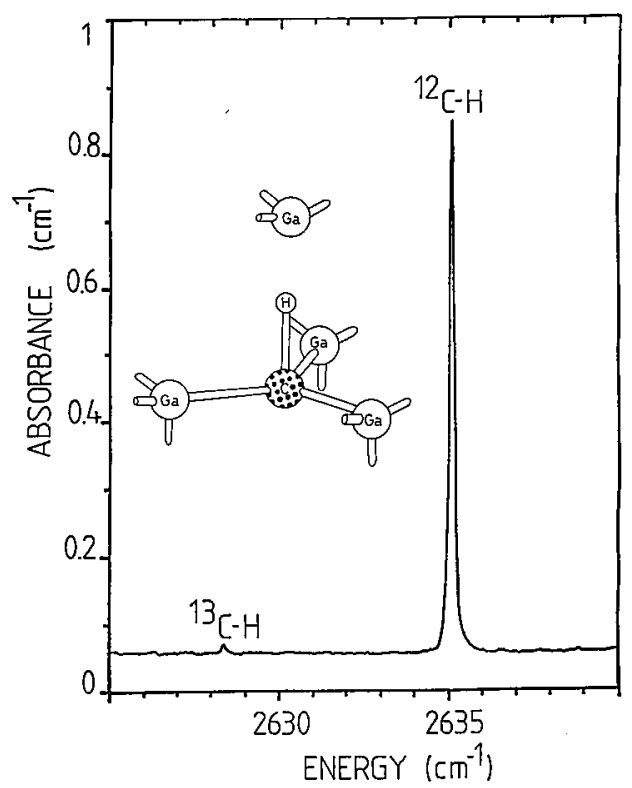

Fig. 4. IR absorption measured at liquid He temperature for the $\mathrm{C}_{\mathrm{As}}-\mathrm{HI}$ complex in GaAs. Both ${ }^{12} \mathrm{C}$ - and ${ }^{13} \mathrm{C}$-related modes are observed. From Clerjaud et al., Ref. [26].

\subsection{Donor-H complexes}

The passivation of $n$-type dopants in Si was demonstrated by Johnson et al. [51] with Hall measurements. The sheet carrier density was decreased for thin $n$-type layers which had been exposed to a hydrogen plasma at $150^{\circ} \mathrm{C}$ while the mobility was increased. Johnson et al. argued that neutral donor-H complexes were formed and the model shown in Fig. $3 \mathrm{~b}$ was proposed on the basis of semiempirical calculations.

In subsequent infrared absorption measurements by Bergman et al. [52], the vibrations of the donor $-\mathrm{H}$ and $-\mathrm{D}$ complexes for the $\mathrm{P}, \mathrm{As}$, and $\mathrm{Sb}$ donors were identified. The H-stretching bands are shown in Fig. 5. II and D wagging vibrations at 810 and $555 \mathrm{~cm}^{-1}$, respectively, were also assigned. The stretching and wagging vibrations have little or no dependence upon the identity of the donor. The infrared 


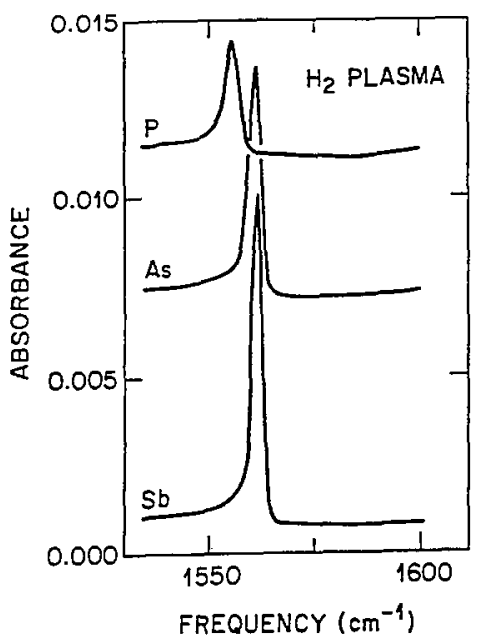

Fig. 5. IR absorption bands (measured near liquid IIe temperature) for P-, As-, and $\mathrm{Sb}$-doped $\mathrm{Si}$ samples which had been passivated in an $\mathrm{H}_{2}$ plasma. From Bergman et al., Ref. [52].

absorption data confirm the existence of the donor-II complexes. Further, Bergman et al. argued that if the II were attached directly to the donor atom, one would expect a greater dependence of the vibrational frequencies upon the identity of the donor. The symmetry of the donor-H complexes and the mode assignments were confirmed in a subsequent uniaxial stress study [53].

Several groups have performed total energy calculations for the P-II complex to determine the minimum energy configuration of the complex $[36,38,54-57]$. The measured vibrational frequencies have provided an important test of the different models. The various calculations have found that the configuration with II at the $\mathrm{AB}$ site adjacent to the $\mathrm{Si}$ atom has lowest energy. Ilowever, the II-stretching frequencies which were calculated were either too large, i.e. near $2150 \mathrm{~cm}^{-1}[51,54-55]$, or much too small, i.e. near $400 \mathrm{~cm}^{-1}$ [36].

The problem associated with calculating the vibrational frequencies for the donor-II complexes has been resolved in recent calculations by Zhang and Chadi [56] and Denteneer et al. [57] for the P-II complex. Both sets of authors find that for the most stable configuration of the P-II complex, the Si atom to which the $\mathrm{H}$ atom is attached moves substantially ( $0.6 \AA$ from its unrelaxed site) away from the $P$. The configuration without relaxation is a local minimum which has a total energy which is roughly $0.1 \mathrm{eV}$ above the relaxed configuration. With this relaxation included, the measured vibrational frequencies are well accounted for. Hence, the combination of vibrational spectroscopy and computational theory have helped to identify a subtle relaxation for the donor-II complexes.

Chevallier et al. [58] demonstrated donor passivation in GaAs before it was known that donors could be passivated in Si. Subsequently, all of the important 
donor dopants in GaAs have been shown to be passivated by $\mathrm{II}_{2}$ plasma exposure [59]. The most complete study of the vibrational spectra of a donor-II complex in GaAs has been performed by Pajot et al. [60] for $\mathrm{Si}_{\mathrm{Ga}}-\mathrm{II}$. The H-stretching frequency of this complex is at $1717.3 \mathrm{~cm}^{-1}$ (Fig. 6). A doubly degenerate wagging vibration at $896.8 \mathrm{~cm}^{-1}$ has also been assigned to this complex.

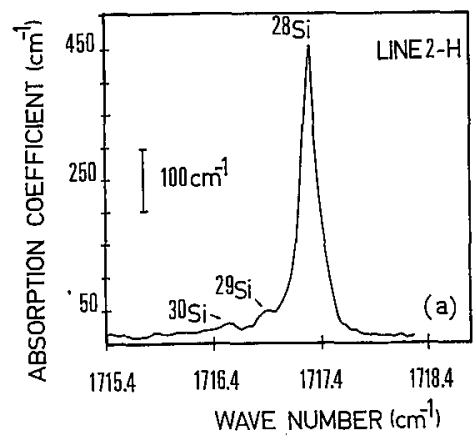

Fig. 6. IR absorption spectrum measured at $6 \mathrm{~K}$ for the II-stretching mode of the GaAs:Si $\mathrm{Ga}_{\mathrm{a}}-\mathrm{H}$ complex. From Pajot et al., Ref. [60].

Superficially, the vibrational spectra for $\mathrm{Si}_{\mathrm{Ga}}$-II [60] resemble the spectra for the donor-H complexes in Si [52] discussed above. The II-stretching modes are at a relatively low frequency (compared to the $>2000 \mathrm{~cm}^{-1}$ vibrations which are typical of the acceptor- $\mathrm{II}$ complexes) and there are similar wagging bands. However, for GaAs: $\mathrm{Si}_{\mathrm{Ga}}-\mathrm{H}$, there is strong evidence that the $\mathrm{II}$ is attached to the donor itself (Fig. 3c), unlike for donor-H complexes in Si. Pajot et al. [60] identified two additional, weak side bands in the $\mathrm{H}$-stretching spectrum (Fig. 6) which were assigned to $\mathrm{Si}_{\mathrm{Ga}}-\mathrm{II}$ complexes that include ${ }^{29} \mathrm{Si}$ and ${ }^{30} \mathrm{Si}$, proving that the $\mathrm{Si}$ donor atom is involved in the $\mathrm{H}$-stretching vibration. The relative intensities of the side bands are consistent with the natural abundances of the Si isotopes.

Briddon and Jones $[22,46]$ found a minimum total energy with the II attached to the $\mathrm{Si}$ atom at the $\mathrm{AB}$ site. In their calculation the $\mathrm{Si}$ atom relaxes along the $C_{3}$ axis of the defect toward the $\mathrm{H}$ atom. This relaxation is similar to the relaxation found for the donor- $\mathrm{H}$ complexes in the $\mathrm{Si}$ host. These authors also calculated vibrational frequencies for their minimum energy configuration which are in reasonable agreement with experiment.

\section{Dissociation of dopant-H complexes}

Dopant-H pairs dissociate upon annealing for temperatures near a few hundred degrees centigrade. Several reactions occur which include the dissociation process itself, retrapping of $\mathrm{H}$ at a dopant site, and the formation of $\mathrm{II}_{2}$ molecules or $\mathrm{H}_{n}$ aggregates. In most early thermal annealing studies, the dissociation kinetics were not first-order and hence it was difficult to obtain a reliable estimate of the dissociation energy. 


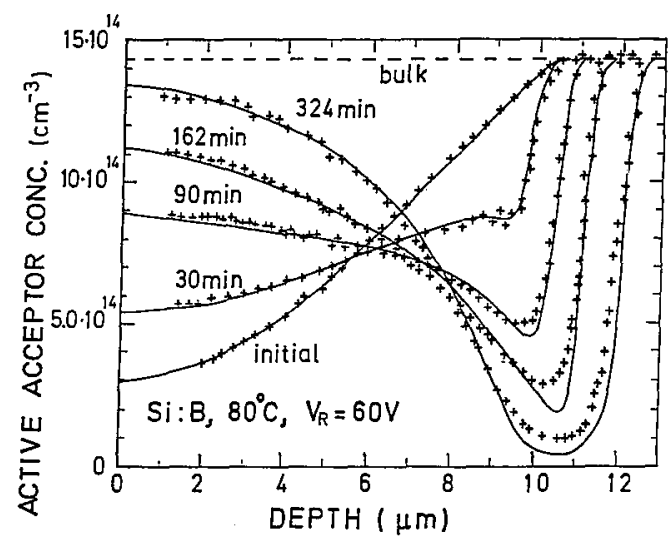

Fig. 7. The active boron concentration in a Schottky barrier diode as a function of the reverse-bias annealing time for a hydrogen plasma exposed, $\mathrm{B}$-doped sample. The $\mathrm{H}_{2}$ plasma exposure was for $2 \mathrm{~h}$ at $120^{\circ} \mathrm{C}$ and a $2 \mu \mathrm{m}$ thick surface layer was removed prior to measurement. From Zundel and Weber, Ref. [61].

Such problems have been overcome recently by Zundel and Weber [61] who have studied the dissociation of acceptor $-\mathrm{H}$ complexes in the junction field of a Schottky barrier diode. The conrentration profile of active acceptors can be determined with $C-V$ measurements. In Fig. 7, it can be seen that annealing in the presence of reverse bias acts to sweep $\mathrm{H}^{+}$from the near surface region of the junction when acceptor-H pairs dissociate; this acts to push the passivated region deeper into the junction. The acceptor-II dissociation in the near-surface region of the device was shown to be accurately described by first-order kinetics. The dissociation energy of the $\mathrm{B}-\mathrm{HI}$ complex has been found to be $1.28 \mathrm{eV}$ [61]. (This energy corresponds to the energy required to fully separate the pair, i.e. the binding energy plus the H-migration energy.) This technique has been applied recently by several groups to study dissociation kinetics of a variety of dopant-II complexes [62-64]. The clever application of junction fields has also been fruitfully applied to study other H-related reactions and II-diffusion [65].

\section{Reorientation kinetics of acceptor-H complexes}

The motion of the light $\mathrm{H}$ atom between equivalent sites has been studied for several dopant- $\mathrm{H}$ complexes. Such motion corresponds to a reorientation of the complex. For a few defect complexes in $\mathrm{Si}$ and $\mathrm{Ge}$, the II moves by tunneling at low temperature. This is the case for $\mathrm{Si}: \mathrm{Be}-\mathrm{H}[66,67]$ and also for the $\mathrm{Ge}: \mathrm{Cu}-\mathrm{H}_{2}[68]$ center. For a few other centers, the motion of the II has been found to be thermally activated. This is the case for Si:B-H [69-71], Si:Cd-II [72], GaAs:Be-H [53], GaAs:Si $\mathrm{As}_{\mathrm{As}}-\mathrm{H}$ [48] and $\mathrm{GaAs}: \mathrm{C}_{\mathrm{As}}-\mathrm{H}$ [49].

For the Si:B-H complex, for example [69], the hydrogen atom occupies one of four crystallographically equivalent $\mathrm{BC}$ sites between the acceptor atom and one of its neighbors. A stress, applied at a temperature sufficiently high for the 
complexes to reorient, can be used to preferentially align the defects. If the temperature is lowered while the stress is maintained, the preferential alignment can be quenched in. This gives rise to an anisotropy in the polarized optical absorption (i.e. a dichroism) for the H-stretching vibration of the complex. The reorientation kinetics of the center can be determined from subsequent measurements of the disappearance of the dichroism upon annealing in the absence of stress. An activation energy for reorientation of $0.19 \mathrm{eV}$ was obtained [69]. (Recent measurements of the $\mathrm{B}-\mathrm{II}$ reorientation rate by anelastic relaxation techniques find a similar activation energy, $0.22 \mathrm{eV}[71]$.)

Why do some centers reorient by tunneling at low temperature while others require thermal energy? Watkins [73] discussed the qualitative difference between situations in which there were substantial relaxations of the hydrogen's heavier neighbors and those that have only a small relaxation of the neighbor atoms. If there are large relaxations which involve $\mathrm{Si}$ motion when the $\mathrm{II}$ moves, then the effective mass of the tunneling species approaches the Si mass, which can reduce the tumneling rate by over 40 decades.

Denteneer et al. [74] have calculated energy surfaces for Si:B-II and Si:Be-II. For both of these defects, the total energy surface has a low energy trough which surrounds the $\mathrm{B}$ or Be. For B-H the global energy minimum is at the $\mathrm{BC}$ site. There is a large relaxation of the $\mathrm{B}$ and $\mathrm{Si}$ atoms along the defect axis that suppresses tunneling. The barrier to reorientation was calculated to be $0.2 \mathrm{eV}$. The agreement with experiment [69-71] is striking and perhaps fortuitous. For the $\mathrm{Si}: B e-I I$ complex, the minimum energy was found for $\mathrm{II}$ near the $\mathrm{C}$ site [74]. There is only a small relaxation of the $\mathrm{Si}$ and $\mathrm{Be}$ atoms. It was argued that the small relaxations make tunneling motions possible.

While the arguments put forward on $\mathrm{H}$ motion are appealing, we emphasize that even for the few systems that have been studied, the results and interpretations are controversial. For example, even though the motion of $\mathrm{H}$ in the B-II complex is thermally activated, Stoneham [75] has noted that thermally assisted tunneling may play a dominant role and that a classical model of hopping over a barrier may not be appropriate to treat the $\mathrm{H}$ motion.

\section{Unintentional dopant passivation}

Atomic hydrogen is often introduced into semiconductors unintentionally during crystal growth and device processing [39, 76, 77]. During the growth of bulk crystals, hydrogen can be introduced from water in the starting materials or in the melt-encapsulant used for the liquid encapsulated Czochralski (LEC) growth of compound materials [76, 78]. Several sharp vibrational features have been attributed to $\mathrm{H}$. In the spectrum which was shown in Fig. 4, the $\mathrm{C}$ and II were unintentional contaminants in $p$-type, LEC-grown GaAs [26]. It is estimated that the concentration of $\mathrm{H}$ can be $10^{16} \mathrm{~cm}^{-3}$ in LEC-grown crystals $[76,79]$.

During epitaxial growth of III-V materials by gas phase techniques like metalorganic chemical vapor deposition (MOCVD) and metalorganic molecular beam epitaxy (MOMBE), hydrogen can be introduced from the source gases [80-86]. $\mathrm{Zn}$-doped InP grown by MOCVD with an InAsP capping layer is cooled down in 
an $\mathrm{AsH}_{3}$ ambient; the $\mathrm{Zn}$ is passivated by hydrogen which is introduced by the pyrolysis of $\mathrm{AsH}_{3}$ at the surface [80, 81]. For epitaxial layers of GaAs:C and related alloys grown from metalorganic sources, an appreciable fraction of the $\mathrm{C}$ has been found to be passivated by hydrogen introduced from the source gases [80-86]. Figure 8 shows infrared absorption spectra of $\mathrm{C}-\mathrm{HI}$ complexes in GaAs:C grown by metalorganic MBE.

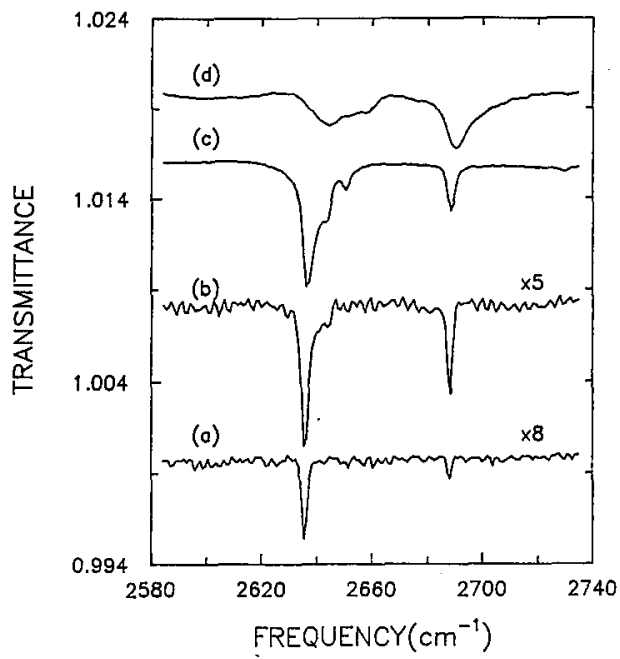

Fig. 8. Infrared absorption spectra of GaAs:C epitaxial layers with different acceptor concentrations grown by MOMBE. The acceptor concentrations are $N_{\mathrm{A}}=$ (a) $6 \times 10^{18} \mathrm{~cm}^{-3}$, (b) $1 \times 10^{20} \mathrm{~cm}^{-3}$, (c) $2 \times 10^{20} \mathrm{~cm}^{-3}$, (d) $4 \times 10^{20} \mathrm{~cm}^{-3}$. Spectra were measured near liquid He temperature. From Stavola et al., Ref. [83].

Plasma processes like reactive ion etching use gaseous mixtures that often include $\mathrm{H}_{2}$ and are an obvious source of atomic hydrogen $[87,88]$. It has also been demonstrated that hydrogen can be introduced during benign processes like polishing, wet etching [76, 77], or annealing in forming gas [83].

As was discussed in Sec. 4, dopant-H complexes dissociate for annealing temperatures between 100 and $500^{\circ} \mathrm{C}$, depending upon the dopant. Hence, it is only necessary to recognize when undesired passivation effects have occurred so that an appropriate anneal can be performed to activate the II-passivated dopants.

\section{Conclusion}

From a fundamental viewpoint, the dopant-hydrogen complexes have provided fertile ground for both experiment and theory. The interplay between vibrational spectroscopy and computational theory has helped to identify defect structures, pathways for H-motions, and subtle relaxations of the defect atoms. There are still many aspects of the hydrogen-defect complexes which are not well understood and much work remains to be done. 
From an applied viewpoint, there are hopes that defect passivation by hydrogen can be exploited to improve materials characteristics or to fabricate device structures. Perhaps it is more important that hydrogen can be introduced in so many ways that unintentional incorporation in device materials seems to be unavoidable. It is likely the hydrogen passivation will continue to affect some processes in which its role or even its presence may not be well known.

\section{Acknowledgments}

We thank S.J. Pearton for a long collaboration on $\mathrm{H}$ in semiconductors and also our colleagues and students at AT\&T Bell Laboratories and Lehigh University who have been involved with this work at various stages. This work was supported by the National Science Foundation under Grant No. DMR - 9023419.

\section{References}

[1] IIydrogen in Semiconductors, Eds. N.M. Johnson, J.I. Pankove, Academic Press, San Diego 1991.

[2] S.J. Pearton, J.W. Corbett, M. Stavola, Hydrogen in Crystalline Semiconductors, Springer-Verlag, Berlin 1992.

[3] Hydrogen in Semiconductors, Eds. M. Stutzmann, J. Chevallier, North-Holland, Amsterdam 1991.

[4] C.G. Van de Walle, in Ref. [1], p. 585; and in: Deep Levels in Semiconductors, 2nd ed., Ed. S.T. Pantelides, Gordon and Breach, New York 1992, to be published.

[5] E.E. Haller, in Ref. [1], p. 351; in Ref. [3], p. 351.

[6] S.J. Pearton, in Ref. [1], p. 65.

[7] C.T. Sah, J.Y.-C. Sun, J.J. Tzou, Appl. Phys. Lett. 43, 204 (1983); C.T. Sah, J.Y.-C. Sun, J.J. Tzou, S.C.-S. Pan, Appl. Phys. Lett. 43, 962 (1983).

[8] J.I. Pankove, D.E. Carlson, J.E. Berkeyheiser, R.O. Wance, Phys. Rev. Lett. 51, 2224 (1983).

[9] G.G. DeLeo, W.B. Fowler, in Ref. [1], p. 511; G.G. DeLeo, in Ref. [3], p. 295.

[10] N.M. Johnson, Phys. Rev. B 31, 5525 (1985).

[11] A. Van Wieringen, N. Warmholtz, Physica 22, 849 (1956).

[12] S.J. Pearton, J.W. Corbett, J.T. Borenstein, in Ref. [3], p. 85.

[13] C. Herring, N.M. Johnson, in Ref. [1], p. 225.

[14] C.G. Van de Walle, P.J.H. Denteneer, Y. Bar-Yam, S.T. Pantelides, Phys. Rev. B 39, 10791 (1989).

[15] S.T. Pantelides, Appl. Phys. Lett. 50, 996 (1987).

[16] A.J. Tavendale, D. Alexiev, A.A. Williams, Appl. Phys. Lett. 47, 316 (1985).

[17] N.M. Johnson, Appl. Phys. Lett. 47, 874 (1985).

[18] A.J. Tavendale, S.J. Pearton, A.A. Williams, Appl. Phys. Lelt. 56, 949 (1990).

[19] J. Zhu, N.M. Johnson, C. Herring, Phys. Rev. B 41, 12354 (1990).

[20] C.H. Seager, R.A. Anderson, Solid State Commun. 76, 285 (1990).

[21] L. Pavesi, P. Giannozzi, F.K. Reinhart, Phys. Rev. B 42, 1864 (1990). 
[22] P. Briddon, R. Jones, in: Shallow Impurities in Semiconductors 1988, Ed. B. Monemar, IOP, Bristol 1989, p. 459.

[23] A.A. Tavendale, S.J. Pearton, A.A. Williams, D. Alexiev, Appl. Phys. Lelt. 56, 1457 (1990).

[24] A.W.R. Leitch, Th. Prescha, J. Weber, Phys. Rev. B 44, 1375 (1991).

[25] M.H. Yuan, L.P. Wang, S.X. Jin, J.J. Chen, G.G. Qin, Appl. Phys. Lell. 58, 925 (1991).

[26] B. Clerjaud, F. Gendron, M. Krause, W. Ulrici, Phys. Rev. Lett. 65, 1800 (1990).

[27] M. Stavola, S.J. Pearton, in Ref. [3], p. 139.

[28] J.I. Pankove, P.J. Zanzucchi, C.W. Magee, G. Lucovsky, Appl. Phys. Lelt. 46, 421 (1985).

[29] G.G. DeLeo, W.B. Fowler, J. Electron. Mater. 14a, 745 (1985); Phys. Rev. B 31, 6861 (1985).

[30] L.V.C. Assali, J.R. Leite, Phys. Rev. Lett. 55, 980 (1985); 56, 403 (1986).

[31] M. Stavola, S.J. Pearton, J. Lopata, W.C. Dautremont-Smith, Appl. Phys. Lett. 50 , 1086 (1987).

[32] C.P. Herrero, M. Stutzmann, Phys. Rev. B 38, 12668 (1988).

[33] B. Bech Nielsen, J.U. Andersen, S.J. Pearton, Phys. Rev. Lett. 60, 321 (1988).

[34] A.D. Marwick, G.S. Oehrlein, N.M. Johnson, Phys. Rev. B 36, 4539 (1987).

[35] A. Amore-Bonapasta, A. Lapiccirella, N. Tomassini, M. Capizzi, Phys. Rev. B 36, 6228 (1987).

[36] K.J. Chang, D.J. Chadi, Phys. Rev. Lett. 60, 1422 (1988).

[37] P.J.H. Denteneer, C.G. Van de Walle, S.T. Pantelides, Phys. Rev. B 39, 10809 (1989).

[38] S.K. Estreicher, L. Throckmorton, D.S. Marynick, Phys. Rev. B 39, 13241 (1989).

[39] J. Chevallier, B. Clerjaud, B. Pajot, in Ref. [1], p. 447.

[40] B. Pajot, in: Impurities, Defects and Diffusion in Semiconductors: Bulk and Layered Structures, Ed. D.J. Wolford, J. Bernholc, E.E. Haller, MRS, Pittsburgh, 1990, p. 465.

[41] B. Pajot, B. Clerjaud, J. Chevallier, in Ref. [3], p. 371.

[42] N.M. Johnson, R.D. Burnham, R.A. Street, R.L. Thornton, Phys. Rev. B 33, 1102 (1986).

[43] B. Pajot, A. Jalil, J. Chevallier, R. Azoulay, Semicond. Sci. Technol. 2, 305 (1987).

[44] P.S. Nandhra, R.C. Newman, B. Pajot, J. Chevallier, R.B. Beall, J.J. IIarris, Semicond. Sci. Technol. 3, 356 (1988).

[45] M. Stavola, S.J. Pearton, J. Lopata, C.R. Abernathy, K. Bergman, Phys. Rev. B 39, 8051 (1989).

[46] P. Briddon, R. Jones, in: Shallow Impurities in Semiconductors, Ed. G. Davies, Trans Tech, Switzerland 1991, p. 169.

[47] J. Chevallier, B. Pajot, A. Jalil, R. Mostefaoui, R. Rahbi, M.C. Boissy, in: Defects in Electronic Materials, Eds. M. Stavola, S.J. Pearton, G. Davies, MRS, Pittsburgh 1988, p. 337.

[48] D.M. Kozuch, M. Stavola, S.J. Pearton, J. Lopata, Bull. Am. Phys. Soc. 37, 195 (1992). 
[49] B. Clerjaud, D. Cote, F. Gendron, W.-S. Hahn, M. Krause, C. Porte, W. Ulrici, in: Defects in Semiconductors 16, Eds. G. Davies, G.G. DeLeo, M. Stavola, Trans Tech, Switzerland 1992, p. 563.

[50] R. Jones, S. Öberg, Phys. Rev. B 44, 3673 (1991).

[51] N.M. Johnson, C. Herring, D.J. Chadi, Phys. Rev. Lelt. 56, 769 (1986).

[52] K. Bergman, M. Stavola, S.J. Pearton, J. Lopata, Phys. Rev. B 37, 2770 (1988).

[53] K. Bergman, M. Stavola, S.J. Pearton, T. Hayes, Phys. Rev. B 38, 9643 (1988).

[54] A. Amore-Bonapasta, A. Lapiccirella, N. Tomassini, M. Capizzi, Phys. Rev. B 39, 12630 (1989).

[55] G.G. DeLeo, W.B. Fowler, T.M. Sudol, K.J. O'Brien, Phys. Rev. B 41, 7581 (1990).

·56] S.B. Zhang, D.J. Chadi, Phys. Rev. B 41, 3882 (1990).

[57] P.J.H. Denteneer, C.G. Van de Walle, S.T. Pantelides, Phys. Rev. B 41, 3885 (1990).

[58] J. Chevallier, W.C. Dautremont-Smith, C.W. Tu, S.J. Pearton, Appl. Phys. Lett. 47, 108 (1985).

[59] S.J. Pearton, W.C. Dautremont-Smith, J. Chevallier, C.W. Tu, K.D. Cummings, J. Appl. Phys. 59, 2821 (1986).

[60] B. Pajot, R.C. Newman, R. Murray, A. Jalil, J. Chevallier, R. Azoulay, Phys. Rev. B 37, 4188 (1988).

[61] T. Zundel, J. Weber, Phys. Rev. B 39, 13549 (1989).

[62] S.J. Pearton, J. Lopata, Appl. Phys. Lelt. 59, 2811 (1991).

[63] S.J. Pearton, C.R. Abernathy, J. Lopata, Appl. Phys. Lett. 59, 3571 (1991).

[64] G. Roos, N.M. Johnson, C. Herring, J.S. Herring, Appl. Phys. Lett. 59, 461 (1991).

[65] T. Zundel, J. Weber, Phys. Rev. B 43, 4361 (1991); Phys. Rev. B, to be published.

[66] K. Muro, A.J. Sievers, Phys. Rev. Lett. 57, 897 (1986).

[67] R.E. Peale, K. Muro, A.J. Sievers, Phys. Rev. B 41, 5881 (1990).

[68] J.M. Kahn, L.M. Falicov, E.E. Haller, Phys. Rev. Lell. 57, 2077 (1986).

[69] M. Stavola, K. Bergman, S.J. Pearton, J. Lopata, Phys. Rev. Lelt. 61, 2786 (1988).

[70] C.P. Herrero, M. Stutzmann, Solid State Commun. 68, 1085 (1988).

[71] G. Cannelli, R. Cantelli, M. Capizzi, C. Coluzza, F. Cordero, A. Frova, A. Lo Presti, Phys. Rev. B 44, 11486 (1991).

[72] M. Gephard, B. Vogt, W. Witthuhn, Phys. Rev. Lell. 67, 847 (1991).

[73] G.D. Watkins, in: Defects in Semiconduclors 15, Ed. G. Ferenczi, Trans Tech, Switzerland 1989 , p. 39.

[74] P.J.H. Denteneer, C.G. Van de Walle, S.T. Pantelides, Phys. Rev. Lelt. 62, 1984 (1989).

[75] A.M. Stoneham, Phys. Rev. Lett. 63, 1027 (1989).

[76] B. Clerjaud, in Ref. [3], p. 383.

[77] S. Pearton, M. Stavola, J.W. Corbett, Adv. Maler. 4, 341 (1992).

[78] B. Clerjaud, D. Cote, C. Naud, Phys. Rev. Lett. 58, 1755 (1987); B. Clerjaud, D. Cote, W.-S. Hahn, W. Ulrici, Appl. Phys. Lett. 58, 1860 (1991).

[79] B. Clerjaud, D. Cote, C. Naud, M. Gauneau, R. Chaplain, Appl. Phys. Lett. 59, 2980 (1991). 
[80] S. Cole, J.S. Evans, M.J. Harlow, A.W. Nelson, S. Wong, Electron. Lelt. 24, 929 (1988).

[81] G.R. Antell, A.T.R. Briggs, B.R. Butler, S.A. Kitching, J.P. Stagg, A. Chew, D.E. Sykes, Appl. Phys. Lett. 53, 758 (1988).

[82] D.M. Kozuch, M. Stavola, S.J. Pearton, C.R. Abernathy, J. Lopata, Appl. Phys. Lett. 57, 2561 (1990).

[83] M. Stavola, D.M. Kozuch, C.R. Abernathy, W.S. Hobson, Advanced III-V Compound Semiconductor Growth, Processing, Devices, Eds. S.J. Pearton, D.K. Sadana, J.M. Zavada, MRS, Pittsburgh 1992.

[84] K. Woodhouse, R.C. Newman, T.J. de Lyon, J.M. Woodall, G.J. Scilla, F. Cardone, Semicond. Sci. Technol. 6, 330 (1991).

[85] T.P. Chin, P.C. Kirchner, J.M. Woodall, C.W. Tu, Appl. Phys. Lett. 59, 2865 (1991).

[86] Y. Axhizawa, T. Noda, K. Morizuka, M. Asaka, M. Obara, J. Cryst. Growth 107, 903 (1991).

[87] R. Cheung, S. Thomas, I. McIntyre, C.D.W. Wilkinson, S.P. Beaumont, J. Vac. Sci. Technol. B 5, 1911 (1988).

[88] T.R. Hayes, W.C. Dautremont-Smith, H.S. Luftman, J.W. Lce, Appl. Phys. Lelt. 55, 56 (1989). 